\title{
High Efficiency Callus Induction and Regeneration of Solanum torvum Plants
}

\author{
Ya-Long Qin, Xiao-Chun Shu, Wei-Bing Zhuang, Feng Peng, \\ and Zhong Wang ${ }^{1}$ \\ Institute of Botany, Jiangsu Province and Chinese Academy of Sciences, \\ Nanjing 210014, China
}

Additional index words. tissue culture, plant regeneration, eggplant

\begin{abstract}
Callus induction and plant regeneration play a key role in transgenic technology. Although much progress has been made with respect to eggplant, this type of research is insufficiently developed in Solanum torvum (a wild relative of eggplant), which contains a large number of resistance genes. Here, a high-efficiency regeneration system of $S$. torvum was established. Stem segments and leaves were cultured on Murashige and Skoog (MS) medium supplemented with $0.5-3.0 \mathrm{mg} \cdot \mathrm{L}^{-1}$ 6-benzyladenine (6-BA) and $0.1-0.6 \mathrm{mg} \cdot \mathrm{L}^{-1} \alpha$-naphthaleneacetic acid (NAA). The highest callus induction ratio $(100 \%)$ was produced on $\mathrm{MS}+1.0 \mathrm{mg} \cdot \mathrm{L}^{-1} \mathbf{6 - B A}+0.5 \mathrm{mg} \cdot \mathrm{L}^{-1} \mathrm{NAA}$. The combination of $0.5 \mathrm{mg} \cdot \mathrm{L}^{-1} \mathrm{BA}$ and $1.0 \mathrm{mg} \cdot \mathrm{L}^{-1}$ 2,4-dichlorophenoxyacetic acid in $\mathrm{MS}$ medium (double microelement) was the best for plant regeneration. Well-developed shoots rooted on half-strength $\mathrm{MS}$ medium supplemented with $0.1 \mathrm{mg} \cdot \mathrm{L}^{-1}$ indole-3acetic acid (IAA). These results will be helpful for functional verification of resistance genes from $S$. torvum and may be useful to those working in the field of eggplant breeding.
\end{abstract}

Solanum torvum of the family Solanaceae, a wild relative of eggplant (Solanum melongena), has been identified to carry multiple traits of resistance to the most serious biological and abiotic stress (i.e., bacteria, fungal wilts, and root-knot nematodes; salt or cadmium stress) (Bagnaresi et al., 2013; Gousset et al., 2005). Transgenic technology, which relies on efficient genetic transformation systems, is the best way to solve these problems, and the target genes, which are strongly resistant and high yielding, can be imported into the cultivated plant to obtain high-quality varieties through genetic engineering (Jin et al., 2004). Regeneration systems have been successfully established in many varieties of Solanum L., including eggplant, potato, and tomato. However, compared with plants of the same genus, the callus differentiation frequency (\%) of $S$. torvum is still relatively low, and there is no stable plant regeneration system for the genetic transformation of $S$. torvum. The purpose of this study was therefore to develop an efficient and reproducible in vitro regeneration protocol for explants of $S$. torvum as a necessary first step for subsequent biotechnological studies and applications.

Received for publication 30 June 2017. Accepted for publication 10 Oct. 2017.

This work was supported by the Natural Science Foundation of Jiangsu Province (BK20140761). The authors are grateful to the editors and referees for their valuable comments that improved our manuscript.

We thank LetPub (www.letpub.com) for its linguistic assistance during the preparation of this manuscript.

${ }^{1}$ Corresponding author. E-mail: wangzhong19@ 163.com.
Choosing appropriate explants is the first step in building an efficient plant regeneration system. Several explants have been used to establish regeneration systems in the Solanum genus, such as anthers, protoplasts, stem segments, leaves, cotyledons, and hypocotyls (Alicchio et al., 1984; Jia and Potrykus, 1981; Matsuoka and Hinata, 1979; Raina and Iyer, 1973; Saxena et al., 1981; Xing et al., 2010). In eggplant, anther culture to obtain transgenic plants from microspore-derived embryos has been studied since the 1980s, and plantlets are regenerated at a satisfactory rate from the callus of eggplant following anther culture (Rotino, 2016). Regenerated plants have also been obtained from shoots of different eggplant varieties such as S. khasianum, S. indicum, and S. sisymbrifolium (Bhatt et al., 1979; Fassuliotis, 1975).

Several experiments in eggplant regeneration have been performed using MS medium supplemented with different plant growth regulators. For instance, MS with thiadiazuron is used for in vitro organogenesis (Magioli et al., 1998), kinetin (KT) is used for anther culture (Rotino, 2016), and NAA is used for somatic embryogenesis (Sharma and Rajam, 1995). In different stages of tissue culture, the hormones and concentrations used are different. Bud induction of cotyledon explants in eggplant is improved by favorable adjustment of ZT, IAA, and sucrose, and shoot elongation occurred in response to MS supplemented with gibberellic acid and AgNO3 (Xing et al., 2010). This article reports a highly efficient callus induction and plant regeneration system for a wild relative of eggplant Solanum torvum through the use of stem segment and leaf explants. The effects of different hormone concentrations on the construction of a high-frequency regeneration system of $S$. torvum were studied to provide theoretical guidance for the rapid development of $S$. torvum tissue culture and genetic engineering breeding.

\section{Materials and Methods}

Plant material. Aseptic S. torvum seedlings were stored in the laboratory of the Institute of Botany, Jiangsu Province, and Chinese Academy of Sciences of Jiangsu, Nanjing, China. The seedlings were placed on MS medium in glass vessels under fluorescent light $\left(100 \mu \mathrm{mol} \cdot \mathrm{m}^{-2} \cdot \mathrm{s}^{-1}\right)$ with a lighting regime of $16: 8 \mathrm{~h}$ (light/dark) at $25 \pm 1{ }^{\circ} \mathrm{C}$.

Callus induction. After being cultured for $30 \mathrm{~d}$, the seedlings were removed from the MS medium. The $1.0 \mathrm{~cm} \times 1.0-\mathrm{cm}$ leaf and $0.5-$ to $1.0-\mathrm{cm}$ stem segments of seedling explants were cut using a sterilized razor and cultured in glass growth vessels containing solidified MS callus induction medium supplemented with different combinations of 6 BA: $0.5,1.0,1.5,2.0,2.5$, and $3.0 \mathrm{mg} \cdot \mathrm{L}^{-1}$ and NAA: $0.1,0.2,0.3,0.4,0.5$, and $0.6 \mathrm{mg} \cdot \mathrm{L}^{-1}$.

Callus proliferation. To obtain quality callus, the medium used in the study of Fang Yanyan was modified and the callus subculture medium MS was added with $0.3 \mathrm{mg} \cdot \mathrm{L}^{-1} \mathrm{NAA}+2.0 \mathrm{mg} \cdot \mathrm{L}^{-1} \mathrm{BA}+1.0 \mathrm{mg} \cdot \mathrm{L}^{-1}$ 2,4-D (Fang, 2013).

Plant regeneration. The organogenic calluses were transferred to different combinations of hormones: NAA + BA, KT + IAA, 2,4-D + KT, BA + 2,4-D, IAA + BA + transzeatin (ZT), and IAA + BA + KT.

Plant multiplication. When the regenerated plantlets of $S$. torvum attained a height of $0.5-1.0 \mathrm{~cm}$, they were transferred to $1 / 2 \mathrm{MS}$ plant medium containing $0.1 \mathrm{mg} \cdot \mathrm{L}^{-1} \mathrm{IAA}$. The plantlets were cultured under fluorescent light for $16 \mathrm{~h}\left(100 \mu \mathrm{mol} \cdot \mathrm{m}^{-2} \cdot \mathrm{s}^{-1}\right)$ at $25 \pm 1{ }^{\circ} \mathrm{C}$. Root induction was scored after $30 \mathrm{~d}$.

Field transfer of the regenerated plantlets. After environmental domestication for $3 \mathrm{~d}$, the well-rooted regenerated plantlets were cleaned and then transferred to pots that contained a soil mixture consisting of $1: 1: 1$ (peat soil:sand:perlite). Plants $\approx 20 \mathrm{~cm}$ tall were transferred to the field, and the plant survival rate was calculated after 1 month under field conditions.

Statistical analysis. The frequency of callus induction and plant regeneration was calculated as below:

$$
\begin{aligned}
& \text { Callus induction frequency }(\%) \\
& \begin{array}{l}
=\text { Number of callus/Number of explants } \\
\times 100 \%
\end{array}
\end{aligned}
$$

Plant regeneration frequency $(\%)$

$=$ Number of callus - regenerated plantlets/ Regenerated callus $\times 100 \%$

Analysis of the frequency was performed to determine the effect of growth-regulating substances. All experiments were repeated three times using 10 replicates. 
Table 1. Effects of BA and NAA in Murashige and Skoog medium on callus induction frequency from stem segments of $S$. torvum.

\begin{tabular}{|c|c|c|c|c|c|c|}
\hline \multirow[b]{2}{*}{$\mathrm{BA}\left(\mathrm{mg} \cdot \mathrm{L}^{-1}\right)$} & \multicolumn{6}{|c|}{$\mathrm{NAA}\left(\mathrm{mg} \cdot \mathrm{L}^{-1}\right)$} \\
\hline & $0.1(\%)$ & $0.2(\%)$ & $0.3(\%)$ & $0.4(\%)$ & $0.5(\%)$ & $0.6(\%)$ \\
\hline$\overline{0.5}$ & $76 \pm 2$ & $74 \pm 1$ & $81 \pm 2$ & $96 \pm 2$ & $100 \pm 0$ & $94 \pm 1$ \\
\hline 1 & $78 \pm 3$ & $85 \pm 3$ & $99 \pm 1$ & $99 \pm 1$ & $98 \pm 1$ & $96 \pm 2$ \\
\hline 1.5 & $73 \pm 2$ & $67 \pm 1$ & $77 \pm 1$ & $85 \pm 2$ & $99 \pm 1$ & $79 \pm 2$ \\
\hline 2 & $43 \pm 3$ & $61 \pm 1$ & $69 \pm 3$ & $82 \pm 3$ & $100 \pm 0$ & $77 \pm 2$ \\
\hline 2.5 & $57 \pm 1$ & $63 \pm 2$ & $72 \pm 3$ & $66 \pm 3$ & $94 \pm 1$ & $71 \pm 2$ \\
\hline 3 & $48 \pm 2$ & $51 \pm 2$ & $43 \pm 2$ & $73 \pm 1$ & $91 \pm 1$ & $56 \pm 3$ \\
\hline
\end{tabular}

$\mathrm{NAA}=\alpha$-naphthaleneacetic acid.

Table 2. Effects of BA and NAA in Murashige and Skoog medium on callus induction frequency from leaves of $S$. torvum.

\begin{tabular}{lcccrrr}
\hline & \multicolumn{5}{c}{$\mathrm{NAA}\left(\mathrm{mg} \cdot \mathrm{L}^{-1}\right)$} \\
$\mathrm{nyyyyy}$ BA $\left(\mathrm{mg} \cdot \mathrm{L}^{-1}\right)$ & $0.1(\%)$ & $0.2(\%)$ & $0.3(\%)$ & $0.4(\%)$ & $0.5(\%)$ & $0.6(\%)$ \\
\hline 0.5 & $79 \pm 2$ & $81 \pm 2$ & $86 \pm 1$ & $94 \pm 2$ & $98 \pm 2$ & $100 \pm 0$ \\
1 & $99 \pm 1$ & $99 \pm 1$ & $99 \pm 1$ & $99 \pm 1$ & $99 \pm 1$ & $99 \pm 1$ \\
1.5 & $83 \pm 2$ & $84 \pm 2$ & $93 \pm 3$ & $99 \pm 1$ & $100 \pm 0$ & $97 \pm 2$ \\
2 & $74 \pm 3$ & $82 \pm 2$ & $87 \pm 2$ & $89 \pm 2$ & $88 \pm 2$ & $92 \pm 1$ \\
2.5 & $79 \pm 1$ & $68 \pm 1$ & $91 \pm 1$ & $81 \pm 2$ & $78 \pm 3$ & $77 \pm 2$ \\
3 & $63 \pm 2$ & $66 \pm 2$ & $75 \pm 2$ & $64 \pm 1$ & $72 \pm 1$ & $69 \pm 2$ \\
\hline
\end{tabular}

$\mathrm{NAA}=\alpha$-naphthaleneacetic acid.

\section{Results}

Callus induction. Callus induction frequency in response to different hormonal combinations of BA and NAA in MS media is presented in Tables 1 and 2, respectively. The combination of $1.0 \mathrm{mg} \cdot \mathrm{L}^{-1} \mathrm{BA}$ and 0.5 $\mathrm{mg} \cdot \mathrm{L}^{-1} \mathrm{NAA}$ in the MS medium was the best for callus induction of both stem segments and leaves, and the frequency was $100 \%$ (Tables 1 and 2; Fig. 1A and B).

Callus proliferation. Calli from stem segments and leaves were cultured on the improved medium $\left(\mathrm{MS}+0.3 \mathrm{mg} \cdot \mathrm{L}^{-1} \mathrm{NAA}+2.0\right.$ $\left.\mathrm{mg} \cdot \mathrm{L}^{-1} \mathrm{BA}+1.0 \mathrm{mg} \cdot \mathrm{L}^{-1} 2,4-\mathrm{D}\right)$. This innovative medium was necessary for appropriate transformation of the callus (compact, dry, green-yellow, and fast-growing) (Fig. 1C).

Plant regeneration. The prolific callus was cultured on MS regeneration medium (MS medium containing different concentrations of BA and 2,4-D) for plant regeneration. The maximum regeneration frequency was
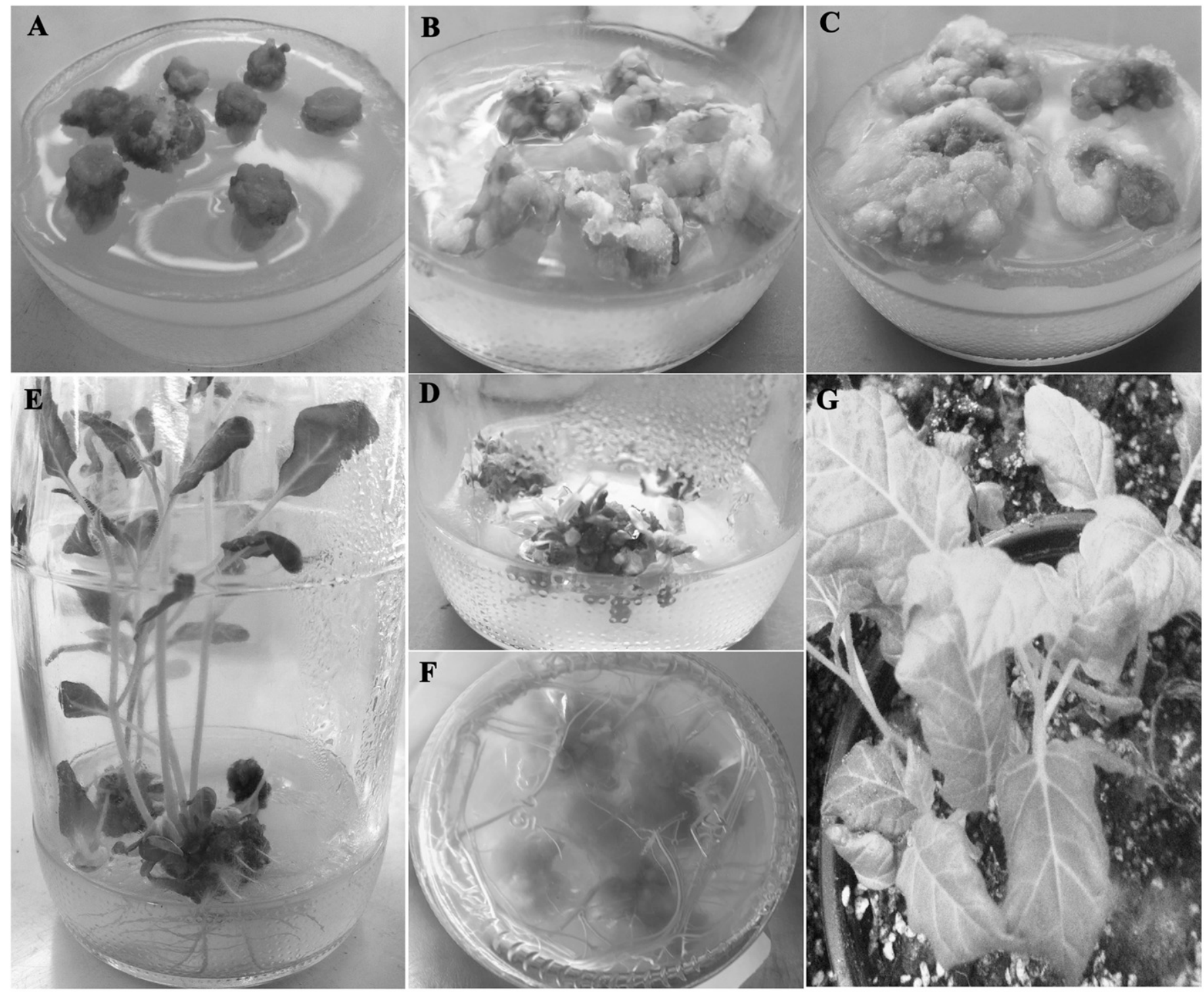

Fig. 1. Callus induction and plant regeneration from stem segments and leaves of S. torvum. (A) Induction of callus from stem segments of S. torvum. (B) Induction of callus from leaves of $S$. torvum. (C) Proliferation of S. torvum callus. (D) Plant regeneration from leaves of S. torvum. (E and F) Plant multiplication from regenerated plantlets. (G) Transferring the regenerated plants to pots in the greenhouse. 
Table 3. Effects of BA and 2,4-D in Murashige and Skoog medium on plant regeneration frequency from leaves of S. torvum.

\begin{tabular}{lcccccc}
\hline & \multicolumn{5}{c}{$2,4-\mathrm{D}\left(\mathrm{mg} \cdot \mathrm{L}^{-1}\right)$} \\
\cline { 2 - 7 } BA $\left(\mathrm{mg} \cdot \mathrm{L}^{-1}\right)$ & $0.5(\%)$ & $1(\%)$ & $1.5(\%)$ & $2(\%)$ & $2.5(\%)$ & $3(\%)$ \\
\hline 0.5 & $45 \pm 1$ & $78 \pm 2$ & $38 \pm 2$ & $14 \pm 1$ & $18 \pm 1$ & 0 \\
1 & $36 \pm 2$ & $73 \pm 1$ & $31 \pm 1$ & $6 \pm 2$ & 0 & 0 \\
1.5 & $31 \pm 1$ & $61 \pm 1$ & $24 \pm 2$ & $4 \pm 1$ & 0 & 0 \\
2 & $11 \pm 2$ & $32 \pm 3$ & 0 & 0 & 0 & 0 \\
2.5 & 0 & $7 \pm 1$ & 0 & 0 & 0 & 0 \\
3 & 0 & 0 & 0 & 0 & 0 & 0 \\
\hline
\end{tabular}

observed in the medium containing $1.0 \mathrm{mg} \cdot \mathrm{L}^{-1}$ 2,4-D and $0.5 \mathrm{mg} \cdot \mathrm{L}^{-1} \mathrm{BA}$; however, the frequency was statistically lower. The double microelement was more suitable for plant regeneration of $S$. torvum, and the frequency of leaf callus regeneration was $78 \%$ (Table 3; Fig. 1D). The different light intensity treatments showed that $50 \mu \mathrm{mol} \cdot \mathrm{m}^{-2} \cdot \mathrm{s}^{-1}$ maintained an appropriate state for plant proliferation. Callus browning is an inevitable problem at a light intensity of $100 \mu \mathrm{mol} \cdot \mathrm{m}^{-2}$ $\cdot \mathrm{s}^{-1}$, and culture under dark conditions leads to vitrification. The results showed that the combination of NAA + BA, KT + IAA, 2,4$\mathrm{D}+\mathrm{KT}$, and IAA $+\mathrm{BA}+\mathrm{ZT}$ in MS medium was not advantageous, that is, there was no budding, and MS containing IAA + BA + KT resulted in very low callus differentiation frequency. The maximum rate of differentiation was measured in response to the medium containing BA and 2,4-D; therefore, this medium (MS medium containing 0.5-3.0 $\mathrm{mg} \cdot \mathrm{L}^{-1} \mathrm{BA}$ and 2,4-D) was selected for plant differentiation. After cultivation in the regeneration medium for $30 \mathrm{~d}$, the regeneration capacity was recorded. Then, based on the most suitable regeneration medium, treatments with different concentrations of microelements and different light intensities were developed to determine the effect on plant regeneration.

Plant multiplication. The regenerated plantlets were transferred to plant multiplication medium. The medium for root generation was highly efficient for S. torvum, and the mean number of roots was 7.3 (Fig. 1E and F).

When the plantlets attained a certain height, they were transferred to the pots; $89 \%$ of the plantlets survived the pot condition (Fig. 1G). When $20 \mathrm{~cm}$ tall, the plantlets were transferred to the field, and a survival rate of $\approx 100 \%$ was recorded.

\section{Discussion}

There are many resistance genes in $S$. torvum; therefore, the production of callus could be advantageous for genetic engineering and rapid development of new varieties in Solanum L. resistance-related genes, such as $V e$ (including $V e 1$ and $V e$ 2), NPRI, and StoCYP77A2 were expressed in tomato, potato, and tobacco in response to Verticillium dahliae infection (Deng-wei et al., 2014; Fradin, 2011; Yang et al., 2015). It is very convenient and favorable to study resistance genes hidden in S. torvum, which could occur if a highly efficient transgenic regeneration system of $S$. torvum were to be constructed.

During the course of callus induction under different hormone ratios, callus formation and the proliferation rate differed significantly between two kinds of $S$. torvum explants. In numerous studies on callus induction, BA and NAA were proved to be very important for suitable callus production (Hong et al., 2009). The addition of BA and NAA to MS medium resulted in an even using MS medium without BA and NAA (Gong et al., 2011), and our study measured $100 \%$ callus induction frequency in the medium (MS + $1.0 \mathrm{mg} \cdot \mathrm{L}^{-1} 6-\mathrm{BA}+0.5 \mathrm{mg} \cdot \mathrm{L}^{-1}$ NAA). Our results showed that a combination of $0.5 \mathrm{mg} \cdot \mathrm{L}^{-1} \mathrm{BA}$ and $1.0 \mathrm{mg} \cdot \mathrm{L}^{-1} 2,4-\mathrm{D}$ in $\mathrm{MS}$ medium (double microelement) was optimal for plant regeneration; this combination is similar to the medium used by Hong et al. (2009) for callus culture. In the study by Che (2009), the optimum combination for plant regeneration was $4.5 \mathrm{mg} \cdot \mathrm{L}^{-1} \mathrm{BA}$ and 2.0 $\mathrm{mg} \cdot \mathrm{L}^{-1}$ 2,4-D in B5 medium. Callus differentiation for plant regeneration varies in response to different explants: the maximum differentiation recorded was $38 \%$ for a stem segment callus and $63 \%$ for leaf callus. Hong's and Gong's studies (2009; 2011) achieved similar results: callus was placed in the medium with the same hormone combinations, and different callus induction frequencies were observed. To study the effect of different light intensities on plant regeneration, this study used three light intensities, and appropriate callus proliferation occurred at a light intensity of $50 \mu \mathrm{mol} \cdot \mathrm{m}^{-2} \cdot \mathrm{s}^{-1}$. This result is the same as that obtained in the study by Alicchio et al. (1982). Auxins, usually IAA, are essential for rooting of regenerated plantlets in Solanum tissue culture systems, whereas shoot regeneration is the most successful when the MS medium is replaced by 1/2 MS medium (Zhang et al., 2014). In our study, $1 / 2 \mathrm{MS}$ medium with $0.1 \mathrm{mg} \cdot \mathrm{L}^{-1} \mathrm{IAA}$ were optimal for $S$. torvum rooting, which is consistent with the conclusion reached by $\mathrm{Li}$ (Ye et al., 2014). With these improved protocols, we efficiency produced callus and regenerated plant. The maximum plant callus induction frequency, callus differentiation frequency, and plant survival frequency were observed in S. torvum. and plant regeneration of $S$. torvum were achieved. Various combinations of growth regulators were used in each step of this plant higher frequency of callus induction than that

In conclusion, successful callus induction regeneration system. The addition of both $1.0 \mathrm{mg} \cdot \mathrm{L}^{-1} \mathrm{BA}$ and $0.5 \mathrm{mg} \cdot \mathrm{L}^{-1} \mathrm{NAA}$ to $\mathrm{MS}$ medium resulted in $100 \%$ callus induction frequency. To obtain more organogenesis callus, $\mathrm{MS}+0.5 \mathrm{mg} \cdot \mathrm{L}^{-1} \mathrm{NAA}+1.0 \mathrm{mg} \cdot \mathrm{L}^{-1}$ $\mathrm{BA}+1.0 \mathrm{mg} \cdot \mathrm{L}^{-1}$ 2,4-D was used, which showed a significantly positive effect on callus proliferation. The prolific callus was compact, dry, green-yellow, and fastgrowing after a few days of training. In our study, the callus differentiation frequency reached $78 \%$ in response to the combination of $0.5 \mathrm{mg} \cdot \mathrm{L}^{-1} \mathrm{BA}+1.0 \mathrm{mg} \cdot \mathrm{L}^{-1} 2,4-\mathrm{D}$ in $\mathrm{MS}$ medium (double microelement). The best medium for rooting was $1 / 2$ MS medium supplemented with $0.1 \mathrm{mg} \cdot \mathrm{L}^{-1} \mathrm{IAA}$, and the mean number of roots was 7.3 after $20 \mathrm{~d}$. The regeneration protocol using tissue culture to produce plants with particular characteristics will lay a foundation for further study of plant gene function and improvement of Solanum resistance through genetic engineering. From this perspective, $S$. torvum can be considered as an alternative model plant to study different aspects of plant biology.

\section{Literature Cited}

Alicchio, R., E. Del Grosso, and E. Boschieri 1982. Tissue cultures and plant regeneration from different explants in six cultivars of Solanum melongena. Experientia 38(4):449450.

Alicchio, R., C. Antonioli, and D. Palenzona. 1984. Karyotypic variability in plants of Solanum melongena regenerated from callus grown in presence of culture filtrate of Verticillium dahliae. Theor. Appl. Genet. 67(2-3):267-271.

Bagnaresi, P., T. Sala, T. Irdani, C. Scotto, A. Lamontanara, M. Beretta, G.L. Rotino, S. Sestili, L. Cattivelli, and E. Sabatini. 2013. Solanum torvum responses to the root-knot nematode Meloidogyne incognita. BMC Genomics 14(1):540.

Bhatt, P.N., D.P. Bhat, and I.M. Sussex. 1979 Organ regeneration from leaf discs of Solanum nigrum, S. dulcamara and S. khasianum. Z. Pflanzenphysiol. 95:355-362.

Che, Z. 2009. Study on technique system of the tissue culture in Magnolia officinalis. Fujian Agriculture and Forestry University, Fuzhou, China

Deng-wei, J., C. Min, and Y. Qing. 2014. Cloning and characterization of a Solanum torvum NPRl gene involved in regulating plant resistance to Verticillium dahliae. Acta Physiol. Plant. 36(11):2999-3011.

Fang, Y.Y. 2013. Study on plant regeneration of Solamum torvum and anther culture of hybrid $\mathrm{F}_{1}$ by Solanum melongena $($ ( ) $\times$ Solamum torvum (ठ̊). Guangxi University, Nanning, China

Fassuliotis, G. 1975. Regeneration of whole plants from isolated stem parenchyma cells of Solanum sisymbrifolium. J. Amer. Soc. Hort. Sci. 100:636-638.

Fradin, E.F. 2011. Functional Analysis of the Tomato Ve Resistance Locu Against Verticillium Wilt.

Gong, J., Y.X. Chu, S. Xu, and D.S. Cha. 2011. Cotyledon and hypocotylculture of eggplant in vitro and high efficient system establishment of plant regeneration. Beifang Yuanyi 15:151154

Gousset, C., C. Collonnier, K. Mulya, I. Mariska, G.L. Rotino, P. Besse, P. Besse, A. Servaes, 
and D. Sihachakr. 2005. Solanum torvum, as a useful source of resistance against bacterial and fungal diseases for improvement of eggplant (S. melongena L.). Plant Sci. 168(2):319327.

Hong, X.H., Y.H. Hong, and G. Chen. 2009. The study on tissue culture and plant regeneration system of eggplant. Beifang Yuanyi 6:63-65.

Jia, J. and I. Potrykus. 1981. Mesophyll protoplasts from Solanum melongena var depressum bailey regenerate to fertile plants. Plant Cell Rpt. 1(2):71-72.

Jin, D.D., M.X. Liang, L.B. Xie, and J.F. Li. 2004. Advances in eggplant tissue culture and genetic engineering. Mol. Plant Breed. 2(6): 861-866.

Magioli, C., A.P.M. Rocha, D.E. de Oliveira, and E. Mansu. 1998. Efficient shoot organogenesis of eggplant (Solanum melongena L.) induced by thidiazuron. Plant Cell Rpt. 17:661-663.

Matsuoka, H. and K. Hinata. 1979. NAA-induced organogenesis and embryo genesis in hypocotyl callus of Solanum melongena L. J. Expt. Bot. 30:363-370.

Raina, S.K. and R.D. Iyer. 1973. Differentiation of diploid plants from pollen callus in anther cultures of Solanum melongena L. Z Pflanzenzucht 70:275-280.

Rotino, G.L. 2016. Anther culture in eggplant (Solanum melongena L.). Methods Mol Biol 1359:453-466.

Saxena, P.K., R. Gill, A. Rashid, and S.C. Maheshwari. 1981. Plantlet formation from isolated protoplasts of Solanum melongena L. Protoplasma 106:355-359.

Sharma, P. and M.V. Rajam. 1995. Genotype, explant and position effects on organogenesis and somatic embryogenesis in eggplant (Solanum melongena L.). J. Expt. Bot. 46:135-141.

Xing, Y., Y. Yu, X. Luo, J.N. Zhang, B. Zhao, and Y.D. Guo. 2010. High efficiency organogenesis and analysis of genetic stability of the regenerants in Solanum melongena. Biol. Plant. 54(2): 231-236.

Yang, L., C. Shi, X. Mu, C. Liu, K. Shi, W. Zhu, and Q. Yang. 2015. Cloning and expression of a wild eggplant cytochrome P450 gene, StoCYP77A2, involved in plant resistance to Verticillium dahliae. Plant Biotechnol. Rpt. 9(4): 167-177.

Ye, L., D.D. Jin, and L.B. Xie. 2014. Establishment and optimization of plant regeneration system in eggplant. Heilongjiang Nongye Kexue 9:48-52.

Zhang, G.G., H.Q. Hang, and M.M. Jiang. 2014. Estabilish of eggplant regeneration system. Mol. Plant Breed. 12(4):810-816. 